\title{
Quality and Perceived Usefulness of Process Models
}

\author{
Peter Rittgen \\ University of Borås, 50190 Borås, Sweden \\ Vlerick Leuven Gent Management School, 9000 Gent, Belgium \\ +46334355930 \\ peter.rittgen@hb.se
}

\begin{abstract}
Modeling is now an essential ingredient in business process management and information systems development. The general usefulness of models in these areas is therefore generally accepted. It is also undisputed that the quality of the models has a significant impact on their usefulness. In the literature we can find any number of quality metrics, but hardly any study that investigates their relation with (perceived) usefulness and none that considers their relative impact on usefulness. We take a look at some of the most frequent quality dimensions and their relative impact on the perceived usefulness of models.
\end{abstract}

\section{Categories and Subject Descriptors H.1.0 [Models and Principles]: General}

\section{General Terms}

Management, Measurement, Design, Languages.

\section{Keywords}

Model quality, usefulness of models, business process models.

\section{INTRODUCTION}

In business process management models play a central role today [2]. Business process models, e.g., allow us to develop a collective understanding of core processes of a business and they enable us to assess problems and discover opportunities for improvements $[8,36]$. They can also help us reorganize the business to overcome problems and realize opportunities.

When information systems are developed the role of models is even more crucial. Requirements are documented in the form of models, at least partially, and the architecture and design of the system practically rely completely on a set of respective models $[15,39,46]$. Poor model quality is a common source of failure in system development $[10,42,44]$ and higher model quality usually leads to higher quality of the delivered systems [3, 5, 45].

Under these circumstances it is evident that the quality of models is paramount for the success of (re-)engineering or development efforts. Consequently model quality has been studied thoroughly and a number of quality metrics or measures have been suggested.

Permission to make digital or hard copies of all or part of this work for personal or classroom use is granted without fee provided that copies are not made or distributed for profit or commercial advantage and that copies bear this notice and the full citation on the first page. To copy otherwise, or republish, to post on servers or to redistribute to lists, requires prior specific permission and/or a fee.

SAC'10, March 22-26, 2010, Sierre, Switzerland.

Copyright 2010 ACM 978-1-60558-638-0/10/03 _..\$10.00.
Moody [29] identified more than 50 approaches to model quality ranging from one-dimensional measures to complex frameworks. He criticizes, among others, the proliferation of proposals, the lack of empirical testing and the lack of measurement. To avoid these issues we have chosen a two-stage approach:

First, we select a framework that is grounded in an established theory and empirically tested. This ensures that the relevant quality dimensions are covered and that the framework is reliable (see section 2). Second, we fill the slots in the framework with concrete quality measurements. Again we use only such measurements that are empirically tested (see section 3 ).

The resulting instrument (framework + measurements) is then used in an empirical study to assess the quality of participants' models. While model quality is of prime importance, it is not the ultimate goal. Models are means to achieve other purposes, e.g. the analysis or design of a business process or the development of an information system. We therefore also need to consider their usefulness with respect to the actual goals, i.e. the extent to which they help us in reaching these goals.

Measuring the usefulness of a model implies the assessment of its impact on a subsequent project. But the success of such a project also rests on a number of other factors, which makes isolating the usefulness factor practically impossible. Many researchers therefore use another measurement that can be determined with greater ease and is closely related to usefulness: Perceived usefulness. Details regarding this measurement are discussed in section 3.5.

The measurements of Model Quality and Perceived Usefulness have been applied in an empirical setting. The goal of this study is to determine which quality factors affect the perceived usefulness of models as well as their relative impact, i.e. the strength of the influence of the respective factor. This is elaborated in section 4 .

\section{A FRAMEWORK FOR MODEL QUALITY}

When choosing a quality framework it makes sense to ensure that it is firmly rooted in an established and relevant theory. On the one hand this provides the framework with a level of generality and ensures that all pertinent quality dimensions are covered. On the other hand it also contributes to the validity of the framework. As models are primarily signs, and are in turn made of signs (the model elements), it seems natural to base a quality framework on semiotic theory.

But according to Moody [29] many theory-based frameworks are not empirically tested. Out of the more than 50 approaches he studied only 6 are empirically validated. Only one of them is based on semiotic theory and covers conceptual models in general: Lindland et al. (henceforth called Lindland \& Krogstie). 
The basic ideas of this approach are described in [18-20, 23]. Their model is shown in Figure 1.

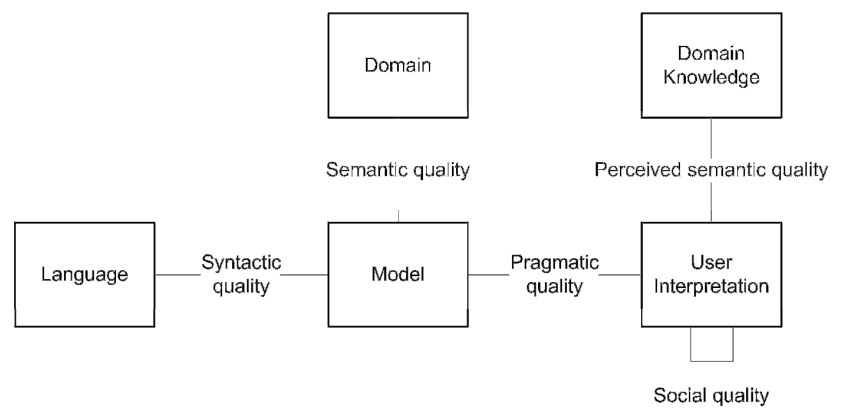

Figure 1. Model quality framework by Lindland \& Krogstie

It distinguishes five quality dimensions: syntactic, semantic, perceived semantic, pragmatic and social quality. Syntactic quality refers to the extent to which the model observes the rules of the modeling language. Pragmatic quality is the degree to which the user's interpretation of the model coincides with the model's meaning. Social quality is defined as the agreement between the interpretations of users. It is relevant because consensus building is a major goal in modeling.

Semantic quality measures the extent to which statements in the model are correct and complete with respect to the domain. Assessing semantic quality is practically impossible as access to the domain is filtered by our perceptions. We can only access our domain knowledge that is a product of the perceptions; it is subjective and does not accurately reflect "the domain" as individual perceptions differ. Domain is rather an abstract notion referring to the collective domain knowledge of a set of individuals.

As semantic quality cannot be measured directly it is common practice to use perceived semantic quality as a proxy $[11,17,26$, $33,37,40,41]$. It measures the degree to which the user's interpretation of the model agrees with his knowledge of the domain. As mentioned above the framework by Lindland \& Krogstie is firmly rooted in semiotic theory and can therefore claim theoretic validity. But the framework has also been tested empirically in laboratory experiments $[30,31]$. Together with the grounding in semiotic theory it is a reliable basis for quality measurement. But the Lindland \& Krogstie framework only specifies the dimensions. It does say how these quality dimensions should be measured. The following section takes up this issue.

\section{MEASURING QUALITY}

The quality dimensions of the Lindland \& Krogstie framework are:

- $\quad$ Syntactic Model Quality (SMQ)

- $\quad$ Perceived Semantic Quality (PSQ)

- $\quad$ Pragmatic Model Quality (PMQ)

- $\quad$ Social Quality (SQ)

\subsection{Syntactic Model Quality}

In our search for a suitable measurement for syntactic quality we found a number of approaches that used modeling conventions as a syntactic metric. An example for that is the work of [21] that is based on the UML (Unified Modeling Language) conventions suggested by [1]. But these are not syntactic constraints in the usual sense. They are rather syntactic realizations of semantic or pragmatic guidelines. For example, the convention "The number of relations between each class and other classes should be small" is not prescribed by UML for Class Diagrams. But it can lead to a more comprehensible model, which is a pragmatic concern.

We have decided to stick to the definition of the Lindland \& Krogstie framework and have therefore excluded such approaches to syntactic quality from consideration as they mix different semiotic categories. The only measure of syntactic quality with a semiotic stance that we found is given in [4]. The authors define it as the weighted sum of syntactic lawfulness and richness. The latter is a property of the language, which was not a variable in our study. We can therefore identify syntactic quality with syntactic lawfulness, which is defined as the ratio of the total breeched rules and the number of statements. In the case of a diagrammatic language this can be translated to the number of syntactic errors divided by the number of nodes and edges.

\subsection{Perceived Semantic Quality}

Perceived Semantic Quality (PSQ) was introduced in [38] and extended in [33] to a 7-indicator measurement. It relies on ideas of the Theory of Reasoned Action [12] but has also undergone substantial empirical validation. The measure has been refined in the course of further experiments based on validity and reliability tests. The result is a consolidated 4-indicator measurement [24] with the indicators correctness, relevance, completeness and authenticity. The authors actually use adjectives but we think that indicators should be nouns. We replaced the term realistic with authenticity because "reality" implies unintended connotations as "reality of a model" is rather understood as "the world described by the model". Table 1 shows each indicator, its definition and the respective statement in the questionnaire judged on a 7-point Likert scale ranging from "strongly disagree" to "strongly agree".

Table 1. Perceived Semantic Quality measurement

\begin{tabular}{|c|c|c|}
\hline Indicator & Definition & Statement \\
\hline $\begin{array}{l}\text { PSQ } \\
\text { Correctness }\end{array}$ & $\begin{array}{l}\text { All statements in the } \\
\text { representation are } \\
\text { correct. }\end{array}$ & $\begin{array}{l}\text { The conceptual model } \\
\text { represents the business } \\
\text { process correctly. }\end{array}$ \\
\hline $\begin{array}{l}\text { PSQ } \\
\text { Relevance }\end{array}$ & $\begin{array}{l}\text { All statements in the } \\
\text { representation are } \\
\text { relevant to the } \\
\text { problem. }\end{array}$ & $\begin{array}{l}\text { All the elements in the } \\
\text { conceptual model are } \\
\text { relevant for the } \\
\text { representation of the } \\
\text { business process. }\end{array}$ \\
\hline $\begin{array}{l}\text { PSQ } \\
\text { Completeness }\end{array}$ & $\begin{array}{l}\text { The representation } \\
\text { contains all } \\
\text { statements about the } \\
\text { domain that are } \\
\text { correct and relevant. }\end{array}$ & $\begin{array}{l}\text { The conceptual model } \\
\text { gives a complete } \\
\text { representation of the } \\
\text { business process. }\end{array}$ \\
\hline $\begin{array}{l}\text { PSQ } \\
\text { Authenticity }\end{array}$ & $\begin{array}{l}\text { The representation } \\
\text { gives a true account } \\
\text { of the domain. }\end{array}$ & $\begin{array}{l}\text { The conceptual model } \\
\text { is a realistic } \\
\text { representation of the } \\
\text { business process. }\end{array}$ \\
\hline
\end{tabular}

The statements were put in front of the participants directly after each session to make sure that their memory is still fresh. This is 
necessary as perceived semantic quality relates the meaning of the model to the reality of the business process as perceived by the participant. This reality emerges in the modeling situation and is not part of the participant's everyday knowledge as it contains parts of the process that are outside the participant's scope of knowledge. To determine a group value for the perceived semantic quality of the model we averaged the scores from the members.

\subsection{Pragmatic Model Quality}

Pragmatic model quality (PMQ) refers to the user's interpretation of the model. This is typically understood as the comprehension or understandability of a model $[13,27]$. The common measure for comprehension involves asking the user a number of questions that relate to meaning of the model and that can only be answered right if the model is understood. For a business process model such a question could be: Does the process model allow for an execution of activity A before activity B? Or: Is it possible that activity $\mathrm{A}$ is not carried out at all? Each correct answer yields a point and the total score is the measure of comprehension.

Six questions were developed for each model and put before the group members 4-6 weeks after they had created it. The time delay was necessary to ensure that the participants have forgotten most of what happened in the session and therefore had to rely completely on the model itself. Comprehension of group members was averaged to yield the understandability of the model.

\subsection{Social Quality}

Social quality (SQ) measures the extent to which interpretations of different users agree with each other. As both the process of arriving at a model and the use of it are collaborative endeavors social quality is an important factor of overall model quality. A measure for social quality was introduced in [16]. It is called Relative Agreement in Interpretation (RAI) and determined as the average mutual agreement among pairs of users w.r.t. their interpretation of the model.

$$
R A I=1-\frac{\left|\left\{s \mid \exists i, j, i \neq j: s \in \mathfrak{I}_{i} \wedge s \notin \mathfrak{I}_{j}\right\}\right|}{\left|M_{E}\right|}
$$

In the formula s stands for a statement of the model. In a process model that could be "There is an activity called Enter PIN code" or "Activity B has to be carried out after activity A". This means that a statement refers to a node or an arc in the process model. $\mathfrak{I}_{i}$ is the interpretation that modeler $i$ associates with the model. It is a set containing all statements that the modeler considers to be true. $M_{E}$ is the set of all explicit statements of the model. In words, a statement is seen as controversial if at least two people have a differing opinion on it. If we divide the number of controversial statements by the overall number of statements, we arrive at the relative disagreement in interpretation. Subtracting this from one yields the RAI.

To operationalize this measure we have developed a social quality questionnaire. For this we have first asked the participants to label all the nodes and arcs with numbers. We then gave them a piece of paper with a table. The first column contained the numbers from 1 to 50 (max. expected node and arc count) in ascending order. The second column was empty. Participants were asked to put a cross in this column for each number of a node or arc that they considered to imply a wrong statement. If a node was in a wrong swim lane they put a $p$ for position instead. They also had to put a circle around the number that represented the total number of nodes + arcs.

Putting the filled-in questionnaires of all group members side by side we counted the number of rows that only showed identical markings, i.e. four empty fields, four crosses or four $p$ 's. This was then divided by the circled number to yield the RAI. The resulting RAI value is already a group value that relates to a single model. The questionnaire for the RAI is administered directly after each session to make sure that the social context is still vivid.

\subsection{Perceived Usefulness of Models}

The measures described in the previous section have mostly been validated in student experiments. There is some criticism related to the use of students for measurement validation as the external validity might be threatened. We agree that this can be the case but it does not disqualify student experiments in general. The quality measures introduced above are based on cognitive aspects, i.e. they focus on the relation between individual and model and disregard the organizational environment. In such cases students are equally good "study objects" as employees.

The situation changes, though, if we consider the (perceived) usefulness of models as the intended use of a model is typically related to an organizational context whereas students often make models as an exercise to learn modeling rather than to put the model to any use. We therefore need a measure that is validated in a business situation. Perceived Usefulness (PU) originated in the Technology Acceptance Model [7, 25], which claims that the use of technology is determined by the (potential) user's perception of its usefulness. Davis [6] defines PU as "the degree to which a person believes that using a particular system would enhance his or her job performance" (p. 320) and introduces a 6-indicator measurement for the usefulness of email.

In the area of modeling, perceived usefulness has also been applied. [22], for example, uses it in the context of decision models but their indicators do not carry over to conceptual models. [28, 31] have suggested a framework for evaluating the perceived usefulness of modeling methods but in the present study we are interested in the perceived usefulness of the models themselves. Such a measure is suggested in [24] but their indicators (improvement over textual description, useful for understanding, performance when understanding) clearly aim at pragmatic quality rather than perceived usefulness. The reason for this is that they look at a teaching situation where understanding the domain is the primary use of models. But in a business context there are a number of other uses.

We have therefore decided to use the original measure suggested in [6]. It has been widely used for different kinds of artifacts. As models fall into this category, Davis' measure is suitable for this purpose. For the sake of this study we have reduced the original number of indicators to 3 , though, as the quality measures already involve a many indicators. To ensure validity and reliability of the instrument we have chosen the indicators with the highest factor loadings. Table 2 shows indicators and respective statements. We have replaced "electronic mail" by "models". 
Table 2. Perceived Usefulness measurement

\begin{tabular}{l|l}
\hline Indicator & Statement \\
\hline PU Performance & Using models improves my job performance. \\
PU & Using models enhances my effectiveness on \\
Effectiveness & the job. \\
PU Productivity & Using models increases my productivity. \\
\hline
\end{tabular}

The statements were put before all participants with instructions to score each statement on a 7-point Likert scale. Again we averaged the scores over each group to get a model score.

\section{THE IMPACT OF MODEL QUALITY ON PERCEIVED USEFULNESS}

The instruments we presented so far were used in an empirical study where we investigated the impact of model quality on the perceived usefulness of models. Most of the studies we mentioned took place in an academic setting, which in our opinion is not suitable as the full use of models is only realized in a business environment. The cited research on quality and usefulness is also mostly restricted to a single quality factor. Multiple-factor studies often neglect the issue of usefulness which is paramount from a business perspective where costs associated with modeling must be balanced by corresponding benefits.

We therefore claim that our study is the first to combine:

- Investigation of a complete set of relevant quality factors of models from a semiotic perspective

- $\quad$ Studying the impact of these quality factors on the perceived usefulness of models

- Collecting data in a business setting

\subsection{Empirical set-up}

The study was performed within an action-research project for a manufacturer of mobile network components. The objective was a business process analysis of the customer distribution center that handles the complete logistics operation. The ultimate purpose of this analysis was to support the requirements specification for a warehouse management system supporting the logistics processes. The software department was in charge of the project and decided to use UML Activity Diagrams for process modeling [32].

In the course of the project 42 models were developed and we decided to follow up this and collect empirical data. Modeling was performed in teams that consisted of 3 to 6 persons that conducted 2 to 4 sessions. Each session resulted in the development of a model. For the modeling sessions we used a collaborative approach that allowed the participants to take an active role in modeling by proposing models. This approach is described in detail in [35]. Most teams had a facilitator. Teams that consisted mostly of software people did not have a facilitator but decided on acceptance of model versions by mutual agreement.

A total of 58 people were involved including software developers, purchasers, sales people, logistics managers, project managers, process managers and operations staff from the logistics unit. Modeling was done with COMA (http://www.COMA.nu), a toolsupported method for collaborative modeling in UML.

\subsection{Data collection}

For PSQ and SQ the questions were administered directly after a modeling session to make sure that the participants still have a fresh memory of it. A printout of the models was available, too, to support group members in judging model quality.

For pragmatic quality we posed 6 questions of comprehension as outlined above regarding the output of each group. Each member received a printout of the models and was asked the questions 4-6 weeks after the modeling session. The average number of correct answers was recorded as the variable PMQ Understandability.

The number of errors, nodes and edges were counted manually for each diagram. The ratio was recorded as variable SMQ.

The instrument for perceived usefulness was also administered 4 to 6 weeks after the project was finished. This was done to ensure that the participants had sufficient time to make use of the models that were produced in the project. In this way they were able to form a judgment regarding the impact the models had on their actual work. By the time we administered the third instrument the requirements specification for the warehouse management system was due, which was the primary purpose of the business process models. If the models helped specify the requirements, their perceived usefulness should be high and; and if model quality is decisive for their usefulness that should also be visible in the data.

\subsection{Data analysis}

To assess the impact of independent on dependent variables factor analysis is the common tool to be used. But as the sample size in our case was quite small we have decided to apply a pair-wise correlation analysis instead. The Kolmogorov-Smirnov test shows that the data is not normally distributed for most of the items as the $p$-value only slightly exceeds the $5 \%$ margin in 3 of the 12 cases. Consequently we decided to apply Spearman's $\rho$ which is more reliable than Pearson for data with an arbitrary distribution and it is only marginally less powerful. We split the results into two tables ( 3 and 4 ) and omitted the upper right triangle, which is identical to the lower left one for reasons of symmetry, and the diagonal which only contains 1 's. The results which are significant on the $1 \%$-level are marked in bold. 
Table 3. Spearman correlations (part 1)

\begin{tabular}{l|l|l|l|l|l}
\hline & & $\begin{array}{l}\text { PSQ } \\
\text { Correctness }\end{array}$ & $\begin{array}{l}\text { PSQ } \\
\text { Relevance }\end{array}$ & $\begin{array}{l}\text { PSQ } \\
\text { Completeness }\end{array}$ & $\begin{array}{l}\text { PSQ } \\
\text { Authenticity }\end{array}$ \\
\hline PSQ Correctness & 0.131 & & & & \\
PSQ Relevance & 0.134 & $\mathbf{0 . 7 2 7}$ & & & \\
PSQ Completeness & 0.049 & $\mathbf{0 . 7 8 2}$ & $\mathbf{0 . 8 4 6}$ & & \\
PSQ Authenticity & 0.106 & $\mathbf{0 . 8 1 2}$ & $\mathbf{0 . 8 9 9}$ & $\mathbf{0 . 8 8 8}$ & \\
PMQ Understandability & 0.198 & 0.259 & $\mathbf{0 . 5 0 7}$ & 0.300 & $\mathbf{0 . 4 0 8}$ \\
SQ & 0.157 & $\mathbf{0 . 6 6 8}$ & $\mathbf{0 . 7 2 6}$ & $\mathbf{0 . 6 3 6}$ & $\mathbf{0 . 7 6 4}$ \\
PU Performance & 0.209 & $\mathbf{0 . 6 9 3}$ & $\mathbf{0 . 7 5 2}$ & $\mathbf{0 . 6 3 4}$ & $\mathbf{0 . 8 3 0}$ \\
PU Effectiveness & 0.174 & $\mathbf{0 . 4 8 9}$ & $\mathbf{0 . 5 3 3}$ & $\mathbf{0 . 3 9 4}$ & $\mathbf{0 . 5 3 0}$ \\
PU Productivity & 0.157 & $\mathbf{0 . 5 9 9}$ & $\mathbf{0 . 6 8 1}$ & $\mathbf{0 . 5 4 5}$ & $\mathbf{0 . 7 2 1}$ \\
\hline
\end{tabular}

Table 4. Spearman correlations (part 2)

\begin{tabular}{l|l|l|l|l}
\hline & PMQ & & PU & PU \\
& Understandability & SQ & Performance & Effectiveness \\
\hline SQ & $\mathbf{0 . 5 7 0}$ & & & \\
PU Performance & $\mathbf{0 . 5 4 7}$ & $\mathbf{0 . 8 1 6}$ & & \\
PU Effectiveness & $\mathbf{0 . 7 4 6}$ & $\mathbf{0 . 7 4 9}$ & $\mathbf{0 . 7 5 1}$ & \\
PU Productivity & $\mathbf{0 . 6 3 5}$ & $\mathbf{0 . 8 3 5}$ & $\mathbf{0 . 8 9 6}$ & $\mathbf{0 . 8 8 2}$ \\
\hline
\end{tabular}

Validity and reliability of the measurement instruments were not a primary concern in our study as we relied on established measures that had been tested already. But as we did a complete correlation matrix we checked the inter-item correlations for PSQ, SQ and PU anyway. The former is significant for all 4 indicators with high values of $0.812,0.899$ and 0.888 between Authenticity and the others, which suggests that Authenticity is the prime indicator. This agrees with the results in [24] for the item "realistic".

Table 4 indicates a similar situation for the PU measure. All interitem correlations are significant and the highest values of 0.896 and 0.882 suggest that Productivity is the primary indicator. Again that agrees with the highest factor loading of 0.98 for Productivity in [6]. The construct validity of the PSQ and PU measures has thereby been confirmed once more.

In order to arrive at a suitable graphical model that can explain the relations between the investigated variables we did as follows. We started with a model that contains a node for each variable and an undirected edge for each significant correlation. We then remove all isolated nodes (in this case only SMQ). After that we removed spurious links by deleting edges that shortcut a path where each leg in the path represents a stronger correlation than the one of the shortcut. W.r.t. arrows we assume that quality causes usefulness and that secondary indicators cause the primary ones. For PSQ the latter can be seen in [9] where a single-item measure is used that corresponds to Authenticity.

If we follow this procedure for the data in Table 3 and Table 4 we arrive at the model in Figure 2.

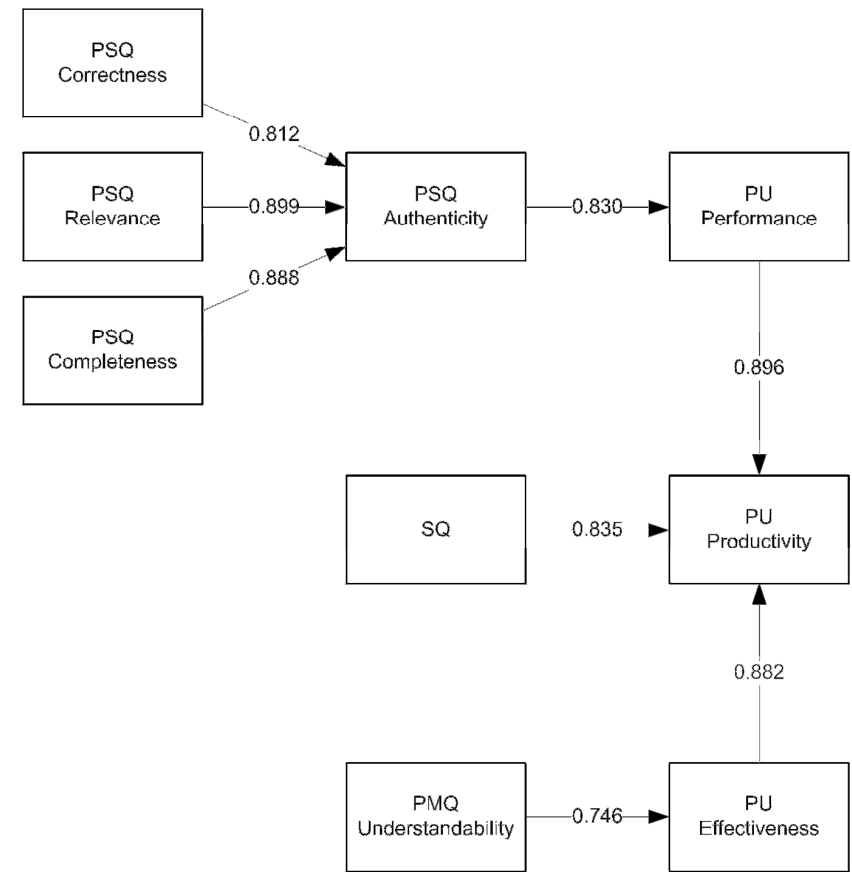

Figure 2. Model Quality and Perceived Usefulness

Correctness, Relevance \& Completeness are secondary indicators of Perceived Semantic Quality. They have a strong correlation with Authenticity, the primary indicator. Together they form a stable and reliable measurement of Perceived Semantic Quality. Of the four original quality dimensions only three are related to Perceived Usefulness. Syntactic Model Quality (SMQ) has no 
correlation to either of the other quality dimensions or PU. The three quality dimensions all have a strong impact on Perceived Usefulness. Both Performance and Effectiveness are secondary indicators of PU whereas Productivity is primary.

The Authenticity dimension of Perceived Semantic Quality has an impact on the Performance item of PU. This is the factor with the strongest influence on Perceived Usefulness. This means that a model which delivers an authentic description of e.g. a business process is likely to increase the job performance of the model user when applying it in e.g. requirements elicitation, and thereby also his productivity. This result partially confirms earlier research, particularly [24], regarding the importance of users' perceptions of semantic quality for the perceived usefulness of models and the intention to make use of these models, and ultimately the success of the re-engineering or development project.

But our study has also shown the importance of two other quality factors that are often neglected even in the studies that refer to the Lindland \& Krogstie framework, which explicitly names these factors: Pragmatic and Social Quality. According to our results, the Pragmatic Model Quality of Understandability has a bearing on the Effectiveness item of Perceived Usefulness. This can be interpreted as follows: If the user of a model has a better understanding of it, he or she can make a more effective use of it, which in turn increases his productivity. E.g., a good understanding of the business process facilitates the identification of requirements on a system that supports this process.

We defined Social Quality as the degree of agreement between users. It is this mutual agreement that is vital for the success of a project that aims to change the organization. Empirical studies have shown that a lack of stakeholder involvement (one source of $\mathrm{SQ}$ ) is at the heart of many failures in change management and system development projects. The Chaos Report constantly names user involvement as the top reason for project success [42, 43].

\section{CONCLUSION}

Models are today at the heart of all projects that strive for substantial changes in organizations. Model quality has therefore been studied extensively over the years and approaches to it abound. Krogstie, and Jørgensen [29] criticize that many of them are of a conceptual nature and are not empirically tested. Even fewer are tested in the field. We have therefore paid attention to choosing those measurements that at least underwent a laboratory test. We claim that this can be sufficient for measures that aim at cognitive aspects of quality where the organizational environment does not carry weight. Even social quality, which involves at the least a number of other people, can be measured reasonably well in a student experiment as the practically equal results for SQ validity in the academic and business contexts of our study show.

But our study goes further than confirming laboratory measures in the field. We also embed quality in a use context by investigating the impact of quality on perceived usefulness as the common proxy for usefulness. It is in this respect that our work goes beyond most related studies that view quality as an isolated phenomenon. We claim that the process of modeling has to be justified economically by demonstrating in a rigorous manner that its products are useful from a business perspective.

It is precisely there that our study makes its main contribution. Based on an established quality framework we select the quality measures with the strongest empirical support and extend this with a new measure for social quality w.r.t. model content. The application of these measurements in a business situation shows the precise nature of the relations between the quality dimensions and perceived usefulness. This allows us to derive a model of the relations between these important constructs.

The perhaps most important finding though is that Social Quality has indeed a strong impact on the prime indicator of Perceived Usefulness of models and therefore also on the intention to use and the actual use as evidenced by the Technology Acceptance Model. This puts the limelight on the modeling process as a collaborative effort. While the other quality dimensions are reasonably covered by existing modeling methods, there is little support for achieving Social Quality in models.

So far most modeling sessions in practice are chauffeured by a facilitator who elicits the necessary information for model construction from the domain experts. As the domain experts have little insight into the process and little understanding of the modeling languages that are used, this procedure is not likely to improve agreement among the participants. We therefore claim that all participants involved must take on a more active role in the process that gives them a better chance to have an impact on the final result. A possible technique for achieving this is setting up the modeling process as a negotiation as suggested in [34]. Another one could be the integration of game elements to stimulate interest and participation in modeling as proposed in [14].

\section{REFERENCES}

[1] Ambler, S.W. The Elements of UML 2.0 Style. Cambridge University Press, Cambridge, UK, 2005.

[2] Becker, J., Rosemann, M. and Uthmann, C.v. Guidelines of Business Process Modeling. in Aalst, W.v.d., Desel, J. and Oberweis, A. eds. Business Process Management, Springer, Berlin, 2000, 241-262.

[3] Browne, G.J. and Ramesh, V. Improving information requirements determination: a cognitive perspective. Information \& Management, 39. 625-645.

[4] Burton-Jones, A., Storey, V.C., Sugumaran, V. and Ahluwalia, P. A semiotic metrics suite for assessing the quality of ontologies. Data \& Knowledge Engineering, 55. 84-102.

[5] Chandra, A. and Krovi, R. Representational congruence and information retrieval: towards an extended model of cognitive fit. Decision Support Systems, 25. 271-288.

[6] Davis, F. Perceived Usefulness, Perceived Ease of Use, and User Acceptance of Information Technology. MIS Quarterly, 13 (3). 319-339.

[7] Davis, F.D., Bagozzi, R.P. and Warshaw, P.R. User acceptance of computer technology: a comparison of two theoretical models. Management Science, 35 (8). 982-1003.

[8] Dietz, J.L.G. Understanding and modeling business processes with DEMO. in Akoka, J., Bouzeghoub, M., Comyn-Wattiau, I. and Métais, E. eds. Proceedings of the 18th International Conference on Conceptual Modeling ER '99, Springer, Berlin, 1999, 188-202. 
[9] Dunn, C.L. and Grabski, S.V. Perceived semantic expressiveness of accounting systems and task accuracy effects. International Journal of Accounting Information Systems Practice, 1 (2). 79-87.

[10] Enders, A. and Rombach, H.D. A Handbook of Software and Systems Engineering: Empirical Observations, Laws and Theories. Addison-Wesley, Reading, MA, 2003.

[11] Fabbrini, F., Fusani, M., Gervasi, V., Gnesi, S. and Ruggieri, S. Achieving quality in natural language requirements. in Proceedings of the Eleventh International Software Quality Week, S. Francisco, CA, Software Research Institute, 1998.

[12] Fishbein, M. and Ajzen, I. Belief, attitude, intention, and behavior: An introduction to theory and research. AddisonWesley, Reading, MA, 1975.

[13] Gemino, A. and Wand, Y. Complexity and clarity in conceptual modeling: Comparison of mandatory and optional properties. Data \& Knowledge Engineering, 55. 301-326.

[14] Hoppenbrouwers, S.J.B.A., Community-based ICT Development as a Multi-Player Game. in What is an Organization? Materiality, Agency and Discourse, (Montreal, 2008), International Communication Association.

[15] Kendall, K.E. and Kendall, J.E. Systems Analysis and Design. Prentice Hall, Upper Saddle River, NJ, 2007.

[16] Krogstie, J. Conceptual Modeling for Computerized Information Systems Support in Organizations, Faculty of Electrical Engineering and Computer Science, The University of Trondheim, Trondheim, 1995.

[17] Krogstie, J. A Semiotic Approach to Quality in Requirements Specifications. in Proceedings of the IFIP TC8 / WG8.1 Working Conference on Organizational Semiotics: Evolving a Science of Information Systems, Kluwer, 2002, 231-249.

[18] Krogstie, J. Using a semiotic framework to evaluate UML for the development of models of high quality. in Siau, K. and Halpin, T. eds. Unified Modeling Language: Systems Analysis, Design, and Development Issues, Idea Group Publishing, 2001, 89-106.

[19] Krogstie, J. and Jørgensen, H.D. Quality of Interactive Models. in Poels, G., Nelson, J., Genero, M. and Piattini, M. eds. Proceedings of the International Workshop on Conceptual Modeling Quality, IWCMQ 02, Tampere, Finland, Springer, Berlin, 2002.

[20] Krogstie, J., Lindland, O.I. and Sindre, G. Towards a deeper understanding of quality in requirements engineering. in Proceedings of the 7th International Conference on Advanced Information Systems Engineering, CAiSE 95, Jyväskylä, Finland, 1995.

[21] Lange, C.F.J., DuBois, B., Chaudron, M.R.V. and Demeyer, S. An Experimental Investigation of UML Modeling Conventions. in Nierstrasz, O., Whittle, J., Harel, D. and Reggio, G. eds. Model Driven Engineering Languages and Systems, 9th International Conference, MoDELS 2006, Genova, Italy, October 1-6, 2006, Proceedings, Springer, Berlin, 2006, 27-41.

[22] Liang, T.-P. and Hung, S.-Y. DSS and EIS applications in Taiwan. Information Technology \& People, 10 (4). 303-315.
[23] Lindland, O.I., Sindre, G. and Sølvberg, A. Understanding quality in conceptual modelling. IEEE Software, 11 (2). 4249.

[24] Maes, A., Poels, G., Gailly, F. and Paemeleire, R. Measuring User Beliefs and Attitudes towards Conceptual Models: A Factor and Structural Equation Model, Ghent University, Ghent, 2005.

[25] Mathieson, K. Predicting user intentions: comparing the technology acceptance model with the theory of planned behavior. Information Systems Research, 2 (3). 173-191.

[26] Matulevicius, R. Validating an Evaluation Framework for Requirements Engineering Tools. in Krogstie, J., Halpin, T.A. and Siau, K. eds. Information Modeling Methods and Methodologies, Idea Group, Hershey, PA, 2005, 148-174.

[27] Mendling, J., Reijers, H.A. and Cardoso, J. What Makes Process Models Understandable? in Alonso, G., Dadam, P. and Rosemann, M. eds. Business Process Management, 5th International Conference, BPM 2007, Brisbane, Australia, September 24-28, 2007, Proceedings, Springer, Berlin, 2007, 48-63.

[28] Moody, D.L. Comparative Evaluation of Large Data Model Representation Methods: The Analysts Perspective. in Spaccapietra, S., March, S.T. and Kambayashi, Y. eds. Conceptual Modeling ER 2002, 21st International Conference on Conceptual Modeling, Tampere, Finland, October 7-11, 2002, Proceedings, Springer, Berlin, 2002, 214-231.

[29] Moody, D.L. Theoretical and practical issues in evaluating the quality of conceptual models: Current state and future directions. Data \& Knowledge Engineering, 15. 243-276.

[30] Moody, D.L., Sindre, G., Brasethvik, T. and Sølvberg, A. Evaluating the quality of information models: empirical analysis of a conceptual model quality framework. in Dillon, L. and Tichy, W. eds. Proceedings of the International Conference on Software Engineering, ICSE 2003, Portland, USA, 2003.

[31] Moody, D.L., Sindre, G., Brasethvik, T. and Sølvberg, A. Evaluating the quality of process models: empirical analysis of a quality framework. in Spaccapietra, S., March, S.T. and Kambayashi, Y. eds. 21st International Conference on Conceptual Modeling, ER 2002, Tampere, Finland, 2002.

[32] OMG. UML 2.0 Superstructure Specification, OMG, Needham; MA, 2004.

[33] Poels, G., Maes, A., Gailly, F. and Paemeleire, R. Measuring the Perceived Semantic Quality of Information Models. in Akoka, J., Liddle, S.W., Song, I.-Y., Bertolotto, M., ComynWattiau, I., Si-Saïd Cherfi, S., Heuvel, W.-J.v.d., Thalheim, B., Kolp, M., Bresciani, P., Trujillo, J., Kop, C. and Mayr, H.C. eds. Perspectives in Conceptual Modeling, Springer, Berlin, 2005, 376-385.

[34] Rittgen, P. Negotiating Models. in Krogstie, J., Opdahl, A. and Sindre, G. eds. Advanced Information Systems Engineering, 19th International Conference, CAiSE 2007, Trondheim, Norway, June 2007, Proceedings, Springer, Berlin, 2007, 561-573. 
[35] Rittgen, Peter: Collaborative Modeling - A Design Science Approach, Proceedings of the 42nd Hawaii International Conference on System Sciences (HICSS-42), Waikoloa, Big Island, Hawaii, USA, January 5-8, 2009, CD-ROM, Los Alamitos, CA: IEEE Computer Society, 2009, 10 p.

[36] Scheer, A.-W. ARIS - Business Process Modeling. Springer, Berlin, 1999.

[37] Schuette, R. Architectures for Evaluating the Quality of Information Models - A Meta and an Object Level Comparison. in Akoka, J., Bouzeghoub, M., Comyn-Wattiau, I. and Métais, E. eds. Conceptual Modeling - ER '99, 18th International Conference on Conceptual Modeling, Paris, France, November 15-18, 1999, Proceedings, Springer, Berlin, 1999, 764-765.

[38] Shanks, G., Tansley, E. and Weber, R. Using ontology to validate conceptual models. Communications of the ACM, 46 (10). 85-89.

[39] Shelly, G.B., Cashman, T.J. and Rosenblatt, H.J. Systems Analysis and Design. Thomson, Boston, MA, 2007.
[40] Siau, K. and Tan, X. Improving the quality of conceptual modeling using cognitive mapping techniques. Data \& Knowledge Engineering, 55 (3). 343-365.

[41] Su, X. and Ilebrekke, L. Using a Semiotic Framework for a Comparative Study of Ontology Languages and Tools. in Krogstie, J., Halpin, T.A. and Siau, K. eds. Information Modeling Methods and Methodologies, Idea Group, Hershey, PA, 2005, 278-299.

[42] The Standish Group The CHAOS Report. The Standish Group International, Dennis, MA, 1994.

[43] The Standish Group The CHAOS Report. The Standish Group International, Dennis, MA, 1999.

[44] The Standish Group Unfinished Voyages. The Standish Group International, Dennis, MA, 1995.

[45] Wand, Y. and Weber, R.A. Research commentary: information systems and conceptual modelling-a research agenda. Information Systems Research, 13 (4). 363-376.

[46] Whitten, J.L. and Bentley, L.D. Systems Analysis and Design Methods. McGraw-Hill, New York, NY, 2007. 